\title{
Antioxidant Status in Relation to Heavy Metals Induced Oxidative Stress in Patients With Polycystic Ovarian Syndrome (PCOS)
}

Manal Abudawood ( $\square$ mabudawoodksu@gmail.com )

King Saud University

Hajera Tabassum

King Saud University

Atheer H. Alanazi

King Saud University

Fatmah Almusallam

King Saud University

Feda Aljaser

King Saud University

Mir Naiman Ali

Riyadh Municipality Central Area Labs

Naif D. Alenzi

National Drug and Cosmetic Control Laboratories (NDCCL), Saudi Food and Drug Authority

Samyah T. Alanazi

King Saud University

Manal A. Alghamdi

National Drug and Cosmetic Control Laboratories (NDCCL), Saudi Food and Drug Authority

Ghadah H. Altoum

National Drug and Cosmetic Control Laboratories (NDCCL), Saudi Food and Drug Authority

Manar A. Alzeer

National Drug and Cosmetic Control Laboratories (NDCCL), Saudi Food and Drug Authority Majed O. Alotaibi

National Drug and Cosmetic Control Laboratories (NDCCL), Saudi Food and Drug Authority

Lulu Alnuaim

Consultant Obstetrician, King Saud University

\section{Research Article}

Keywords: PCOS, oxidative stress, heavy metals

Posted Date: May 6th, 2021 
DOI: https://doi.org/10.21203/rs.3.rs-491791/v1

License: (c) (i) This work is licensed under a Creative Commons Attribution 4.0 International License. Read Full License

Version of Record: A version of this preprint was published at Scientific Reports on November 25th, 2021. See the published version at https://doi.org/10.1038/s41598-021-02120-6. 


\section{Abstract}

Polycystic ovary syndrome (PCOS) is a global health concern in women of reproductive age as $1 / 15^{\text {th }}$ women worldwide, is affected by this syndrome. PCOS is marked by hyperandrogenism, anovulation, menstrual abnormalities, and polycystic ovaries. Metals like arsenic, cadmium, lead and mercury are considered as systemic toxicants/human carcinogens and seems to have devastating effect on the human, even at minimal exposure. One of the probable etiological factor for PCOS identified is oxidative stress. In view of the probable association between oxidative stress, metal toxicity and PCOS, the present study evaluated the role of heavy metal in generation of oxidative stress among females. This prospective study included 106 women (56 women diagnosed with PCOS and 50women who were not diagnosed with PCOS as control women). There was no significant changes in the sociodemographic characteristics between the two groups except with the irregularity in menses and presence of acne. Levels of serum $\mathrm{As}, \mathrm{Cd}, \mathrm{Pb}, \mathrm{Hg}$ increased and serum $\mathrm{GSH}$ and SOD levels diminished significantly in PCOS group compared to control at $P<0.001$. SOD was negatively correlated with $\mathrm{As} \& \mathrm{~Pb}$ at $P<0.05$. Additionally, PCOS group exhibited a strong negative correlation between GSH and $\mathrm{As}(P<0.01), \mathrm{GSH}$ and $\mathrm{Pb}(\mathrm{p}<0.05)$ and $\mathrm{GSH}$ and $\mathrm{Hg}(\mathrm{P}<0.01)$. Furthermore, As correlated positively with increased levels of $\mathrm{Cd}, \mathrm{Pb}$ and $\mathrm{Hg}$ among PCOS women. A significant positive correlation was determined between $\mathrm{Pb} \& \mathrm{Cd}$ and $\mathrm{Cd} \& \mathrm{Hg}$ at $P<0.001$. The outcome of the study provides clear insight of the role of metal induced oxidative stress that plays avitalrole in the pathophysiology underlying PCOS and suggestive of the use of these markers as prognostic tools to circumvent the consequences of high risk exposure to these metals among females.

\section{Introduction}

Approximately $10 \%$ of women are effected by infertility, of which $6.5-8 \%$ of the reproductive age women are effected by polycystic ovary syndrome (PCOS) which constitutes the most prevalence cause of infertility among females ${ }^{1}$. As a type of endocrinopathies, PCOS is characterised by chronic anovulation, menstrualabnormalities (oligomenorrhea or amenorrhea),hyperandrogenism, hyperinsulinemia and polycystic ovaries $^{2,3}$. Yet, the exact etiology underlying PCOS is still unresolved.In biological systems, there are few metals which are essential for the normal physiological functioning such as zinc, iron, and copper in contrast to heavy metals produced as environmental pollutants that have adverse health effects ${ }^{4}$. Environment is constantly being polluted by heavy metals from industries and exposure to these metals is a major area of concern of public health especially for the women of childbearing age as can cause reproductive dysfunction in women ${ }^{5,6}$. The main routes of exposure in environment are soil, air, polluted water, smoking, and food ${ }^{7}$. Quite a few studies have demonstrated the antagonistic effects of heavy metals in utero ${ }^{8,9}$. Heavy metals may induce hormonal changes affecting the menstrual cycle, ovulation, and female fertility ${ }^{10}$. Non-essential metals like lead $(\mathrm{Pb})$, cadmium ( $\mathrm{Cd})$, and arsenic $(\mathrm{As})$, are reproductive toxicants which are widely distributed in the environment and require close monitoring ${ }^{11}$. Role of heavy metal on altering hormonal levels had been evidenced by several epidemiologic studies ${ }^{12-13}$. Yet, studies investigating the impact of heavy metal on etiology of PCOS are scarce. Women with blood Pb levels higher than $25 \mu \mathrm{g} / \mathrm{L}$ were reported to have a 3-fold increasedrisk of infertility compared with women with $\mathrm{Pb}$ levels less than $25 \mu \mathrm{g} / \mathrm{L}^{14}$.Similarly, Cd was reported to influence fertility hormones ; for every $1 \mu \mathrm{g} / \mathrm{L}$ increase in Cd levels, $21 \%$ increase in levels of early 
follicular phase estradiol (E2) levels; serum follicle-stimulating hormone (FSH) and luteinizing hormone (LH) concentrations ${ }^{15}$.

Here, in this report we assume that heavy metals intoxication could lead to oxidativestress (OS) and is accountable for the pathophysiology underlying this disease. Metals like $\mathrm{As}^{16}, \mathrm{Cd}^{17}, \mathrm{Cr}^{18}, \mathrm{~Pb}^{19}$, and $\mathrm{Hg}^{20}$ are graded amongst the most toxic element pertaining to high degree of toxicity and considered systemic toxicants due to multiple organ damage (even at minimal exposure). Metal ions can trigger production of ROS and or has antagonistic action on the antioxidant status of the cell leading to OS.Inevitably, heavy metals can cause conformational changes in DNA and or other nuclear proteins by binding to them and altering events of cell cycle, that might lead to apoptosis/ cancer ${ }^{21}$. In short, several pieces of evidence suggest that metals might be involved in the development of PCOS. However, previous studies in developed settings documented inconsistent findings among PCOS patients in terms of activities of antioxidant status and some with no significant difference reported among PCOS females. Hence, more studies are necessary to further investigate such relationships involving antioxidant status and PCOS.In above perspectives, the current study aimed (a) to determine the serum concentrations of heavy metals and antioxidant markers in PCOS patients and controls; and (b) to identify the correlation between heavy metal concentration and antioxidant markersin PCOS patients.

\section{Result}

The sociodemographic characteristics of PCOS and control groups are outlined in Table 1. Of the total 106 women, $47.1 \%$ were controls and $52.8 \%$ were women with PCOS. Majority of the women were married in age group of 19 to 35 years. Only $2 \%$ of the women were pregnant. Majority of the women were non-pregnant among PCOS and with irregular menses. There was no statistical significance in the sociodemographic features studied in these groups. Yet, a proportion of women demonstrated with irregular menses (56\%) and acne $(60 \%)$ exhibited significant difference in these characteristics. Comparison of biochemical characteristics are shown in Table 2. Serum levels of fasting blood sugar (FBS) and HbA1c were found to increase in PCOS group compared to control. Elevated levels varied significantly at $P<0.001$. Elevated levels of leutinizing hormone (LH) and triglycerides (TG) were found significant in PCOS group at $\mathrm{P}<0.001$ and $\mathrm{P}<$ 0.05 respectively.

Table 3 depicts the serum levels of antioxidant markers and heavy metals among the study groups. The mean values of serum As,Cd, $\mathrm{Hg}$ and Pb varied significantly among PCOS and control groups. Enhanced levels of $\mathrm{As}, \mathrm{Cd}, \mathrm{Pb}$ and $\mathrm{Hg}$ between the two groups are depicted in Fig. 1 (a \& b). It was observed that the levels of heavy metals analyzed were higher in thePCOS group $(P<0.001)$. Contrarily, PCOS patients exhibited diminished levels of SOD and GSH compared to control. Correlation between heavy metals, antioxidant and other metabolic markers was determined from the value of Pearsons correlation ( $r$ ) as shown in Table 4. Interelement relationship of the heavy metals investigated is depicted in Table 5.Most of the elements studied exhibited non-significant correlation with metabolic markers studied -BMI, FBS and lipid profile parameters with an exception to $\mathrm{Hg}$ which demonstrated positive significant correlation with $\mathrm{FBS}$ and $\mathrm{HbA} 1 \mathrm{cat} P<0.001$ and $P<0.05$ respectively. Nevertheless, $C d$ was positively correlated with total cholesterol $(\mathrm{TC})(r=0.30, P<$ 
0.05). A strong significant negative correlation between increased $\mathrm{HbA} 1 \mathrm{c}$ and decreased antioxidant (SOD) at $P<0.001$ was also obtained. Additionally, SOD was significantly correlated with decreased LH at $P<0.05$.

Intriguingly, Pearson correlation performed to evaluate the impact of heavy metals on oxidative stress markers yielded satisfactory results. As, $\mathrm{Pb}$ and $\mathrm{Hg}$ exhibited a strong negative correlation with $\mathrm{GSH}$ at $P<$ $0.01, P<0.05, P<0.01$ respectively. Furthermore, SOD was negatively correlated with $\mathrm{As}$ and $\mathrm{Pb}(P<0.05)$

among PCOS women. Moreover, a strong positive correlation was demonstrated between As and other metals $(\mathrm{Cd}, \mathrm{Pb}$ and $\mathrm{Hg})$ which was statistically significant at $P<0.001$. The correlation determined between $\mathrm{Cd}$ and $\mathrm{Pb}, \mathrm{Cd}$ and $\mathrm{Hg}$ was statistically significant at $P<0.05$ and $P<0.001$ respectively. Serum levels of $\mathrm{Hg}$ and $\mathrm{Pb}$ also exhibited a strong positive correlation, which was statistically significant at $P<0.001$. Multiple regression graph exhibiting correlation between heavy metals and antioxidant markers are depicted in Fig. 2 $\& 3$.

\section{Discussion}

The present study reported the impact of heavy metal on oxidative stress, which constitutes a paramount cause in etiology of PCOS. There was no significant differences in the sociodemographic characteristics between the studied groups yet with some significant variation in the variables like irregular menses and problem of acne. Elevated levels of heavy metals with diminished antioxidant status among PCOS women constitutes the main hallmark findings of the current study. Serum levels of GSH and SOD decreased significantly between the two groups $(P<0.001)$. There was a strong negative correlation between $\mathrm{GSH}$ and As $(P<0.01)$, GSH and $\mathrm{Pb}(P<0.05)$ and GSH and $\mathrm{Hg}(P<0.01)$. SOD was negatively correlated with $\mathrm{As} \& \mathrm{~Pb}$ at $P<0.05$.Furthermore, significant positive correlation was determined between $\mathrm{Pb} \& \mathrm{Cd}, \mathrm{Cd} \& \mathrm{Hg}$ at $P<$ 0.001 .

Heavy metal exposure seems to have devastating effect on the humans. They are considered as systemic toxicants/human carcinogens owing to multiple organ damage they cause ${ }^{6}$. Regardless of a extensive research on PCOS, its etiology is still unknown. Oxidative stress could be one of the paramount cause underlying pathophysiology of PCOS. In view of the existence of correlation between oxidative stress and PCOS, present study hypothesizes the role of heavy metal toxicity in generation of oxidative stress that plays a major role in etiology underlying PCOS.

In the current report, sociodemographic data, oxidative stress biomarkers, and heavy metals (As, $\mathrm{Cd}, \mathrm{Pb} \&$ $\mathrm{Hg}$ )were evaluated between the two study groups. Most of the participants were young and married. Sociodemographic characteristics were less likely to confound the obtained results. Irregular menses (56\%) and acne $(60 \%)$ were some of the variable which differ significantly among the studied groups suggesting that the Saudi women has phenotype similar to South Asian and Omani women owing to proximity in the geographical location and cultural conditions. PCOS women exhibited higher BMI, however the difference between the groups was non-significant. Parallely, in a report in National Health and Nutrition Examination Survey (NHANE), reported no significant correlation between BMI and heavy metals ${ }^{22}$.

Dyslipidemia could be viewed as a possible complication of PCOS, with abnormalities in lipid and lipoprotein metabolism ${ }^{23}$.PCOS women had higher TG compared to controls, yet with no significant changes in the 
levels of TC, HDL-C, and LDL-C. Contradictorily, with regard to altered TG levels, no significant difference in levels of TG was observed between the two groups a Nigerian study ${ }^{24}$.Nevertheless, diminished SOD levels observed in the current report is in homology to the findings reported in Nigerian study. This variation could be attributed to the geographical location and origin. Further the lack of significant association between lipid parameters and heavy metals is reflective of role of lipid profile as independent variable in etiology of PCOS. In addition, LH hormone was negatively correlated with decreased SOD indicating that levels of fertility hormones are under the influence of oxidative stress in human body as is evident in the current report.

As stated previously, heavy metallic elements can act as Endocrine disruptor chemicals (EDCs) by generating OS ${ }^{25,26}$. OS is best defined as disturbances in the normal oxidation reaction of cells with the production of free radicals or reactive oxygen species (ROS) and peroxides that can cause toxic effects/ cell damage. Interestingly, cells harbor molecules that prevent the generation of OS by detoxifying ROS. These molecules which are termed as antioxidants includes highly complex antioxidant enzymatic and non-enzymatic systems. GSH; a non-enzymatic antioxidant and SOD; an enzymatic antioxidant constitutes as prominent antioxidant markerspredicting the status of OS in cellsindirectly. The main hallmark features of the current investigation were the lowered GSG and SOD in PCOS group when compared to control group $(p<0.001)$.GSH functions as an important antioxidant performing vital cellular functions ${ }^{27}$.GSH catalyzes detoxification of oxidizing compounds via its thiol groups ${ }^{28}$. Various chronic conditionsincluding cancer, gastrointestinal and cardiovascular diseases are reported to have lowered antioxidant status ${ }^{29}$.Lowered levels of GSH among PCOS women asevidenced in the current report, are in accordance with previous findings ${ }^{30,31}$. Interestingly, similar trend in antioxidant status was observed with repect to SOD. SOD levels decreased significantly in PCOS women compared to control. SOD is an enzymatic antioxidant which acts catalyzing detoxification of superoxide anions $\left(\mathrm{O}_{2}^{-}\right)$, as a major oxygen radical to $\mathrm{H}_{2} \mathrm{O}_{2}$ and finally to water ${ }^{32}$. SOD exists in different forms with either $\mathrm{Cu} / \mathrm{Zn}, \mathrm{Fe}$ and $\mathrm{Mn}$ as cofactor ${ }^{33}$. Decreased SOD activity and GSH in PCOS women could be due to surplus production of free radicals produced by metal intoxication. On contrary, Yilmaz et al.,2016 reported no significant change between the test and control groups ${ }^{34}$. Parallel to current observation, Hilali et al.,2013 reported diminished antioxidant status among PCOS vs control group ${ }^{35}$. Furthermore, decreased levels of SOD observed in PCOS women in the current study is in homology to previous findings ${ }^{36,37}$ but not with certain other works ${ }^{38}$ that demonstrated significantly higher SOD activity in PCOS patients. The inconsistency in data of SOD might have been due to a compensatory response by the body's defense mechanisms to higher circulating levels of oxidants.

There are numerous sources by which the human are exposed to these heavy metals like occupational exposure ,environmental pollution, and or through food consumption. Although the mechanisms pertaining to the adverse reproductive effects caused by toxic metals have notbeen fully defined, toxicological studies have provided some insights. Yet, evidence of certain heavy metalscontributing to adverse effects on fertility remains incomplete, and knowledge remains fairly limited. Heavy metals including $\mathrm{Cd}, \mathrm{Pb}$, and As are ubiquitous in the environment following many years of industrial use, with most adults having measurable levels of these nonessential elements in their blood. Review from previous reports on the levels of trace elements in PCOS women are conflicting. In a study by Zheng et al.,2015, no significant change was reported in the level of these heavy metals in Chinese women ${ }^{39}$. On contrary, Kirmizi et al.,2020 demonstrated 
increased levels of $\mathrm{Cd}, \mathrm{Hg}$ and $\mathrm{Pb}$ between the two groups ${ }^{30}$. Intriguingly, heavy metals investigated (As, $\mathrm{Cd}$ , $\mathrm{Pb}$ and $\mathrm{Hg}$ ) in the present study exhibited significant increase in the levels of these elements among PCOS women $(P<0.001)$ which are in accordance with previous finding ${ }^{30}$.Nevertheless, with respect to As, levels exhibited significant difference in contrast to the finding of Kirmizi et al.,2020. ${ }^{30}$

$\mathrm{Cd}$ is non-essential element with no physiological or biochemical significance. Leafy vegetables, grains, crustaceans, mushrooms, shellfish, mussels, liver and kidney are few food sources contains adequate amount of $\mathrm{Cd}$ and responsible for $\mathrm{Cd}$ intoxication ${ }^{40}$. Cd intoxication causes deleterious effects on cellular functioning by indirectly synthesizing ROS. Presumably Cd induced OS, includes alteration in the thiol protein, metabolic and endocrine inhibition, alterations of metalloenzymes, DNA and other vital molecules ${ }^{41}$. The reproductive and teratogenic effects of $\mathrm{Cd}$ have seen studied in animal models too. Numerous researches have investigated cadmium relationship with female reproductive disorders. In a Turkish based study on PCOS females, Kurdoglu etal .,2012 reported no significant difference in levels of $\mathrm{Cd}$ and reported lowered $\mathrm{Pb}$ levels among these females ${ }^{42}$. On contrary, the current study observed an increase in serum $\mathrm{Cd}$ among PCOS. Nevertheless, increased $\mathrm{Cd}$ did not exhibited any significant association with antioxidant markers as observed in previous finding ${ }^{30}$.As is found detrimental to human body effecting various organ and organ systems ${ }^{43}$. In addition to $\mathrm{Cd}$ and As, another important environmental toxicant/ pollutant that is widespread is $\mathrm{Hg}$. It is identified to cause adverse health effects by inducing rigorous alterations in human body 44 . Various routes of exposure to $\mathrm{Hg}$ could be through occupational operations, environmental pollution, dental care, preventive medical practices, and industrial and agricultural operations. Notably, dental amalgams and fish are recognized as chronic sources of $\mathrm{Hg}^{45}$. Effect of chronic and relatively low $\mathrm{Hg}$ exposure on are known to inhibit enzymatic activity thereby inducing OS and can be sometimes genotoxic to the cells ${ }^{46} . \mathrm{Hg}$ occupational and experimental exposures have shown that $\mathrm{Hg}$ induces several reproductive and metabolic abnormalities, such as reproductive cyclicity disturbances, irregular ovarian follicular development, ovulation inhibition, infertility, spontaneous miscarriage, increase visceral adiposity, risk of diabetes mellitus, and metabolic syndrome in rodent and human models ${ }^{44,47}$. Besides $\mathrm{As}$ and $\mathrm{Cd}, \mathrm{Pb}$ and $\mathrm{Hg}$ are also known to exert deleterious effects on human health by cellular dysfunction generatingOS. The increased levels of $\mathrm{Hg}$ among PCOS are in line with previous finding ${ }^{30}$.

Further, Pearson correlation performed revealed a significant negative association between antioxidant markers and concentrations of heavy metals investigated (Table 4). Figure $2 \& 3$ depicts the multiple regression analysis between heavy metals and antioxidant markers. Negative correlation between $\mathrm{Pb}$ and antioxidant markers (SOD and GSH) is reflective of the decreased antioxidant status among PCOS females due to oxidation of glutathione causing reduction of serum GSH levels ${ }^{30}$. Nonetheless, elevated levels of serum $\mathrm{Hg}$ in PCOS females correlated negatively with GSH levels indicating the oxidative property of $\mathrm{Hg}$ in generation of OS. Further exploring the inter-element relationship between the heavy metals, the present study demonstrated a significant positive correlation among the heavy metals ( $\mathrm{As}, \mathrm{Cd}, \mathrm{Pb}$ and $\mathrm{Hg}$ ) indicating the pathophysiology developed in PCOS are probably due to enhanced levels of these heavy metals that works in consortium leading to OS.

\section{Conclusion}


Results obtained in the present study is indicative of role of heavy metals induced oxidative stress as one of the vital etiological factor involved in pathogenesis of PCOS. Oxidative stress and heavy metal toxicity should be regularly monitored in females to overcome the risk of developing PCOS. These tests must be integrated in diagnosis of PCOS along with conventional biochemical parameters from early stages to ensure healthy status among females of reproductive age.

\section{Methodology}

This case controlled study consisted of two groups of women in the age group 19 to 35 years - Group-l; Control (56) and Group-II; PCOS patients (50). Patients were screened based on Rotterdam criteria [11] and categorised into PCOS positive if having atleast two features $-a)$ oligo or amenorrhea $(<8$ menstrual cycles in the current year), b) hyperandrogenism and c) polycystic ovaries. Healthy females with no symptoms of hyperandrogenism, history of menstrual dysfunction, infertility, or sonographic signs of PCOS were treated as controls. This study was carried out in the Department of Clinical laboratory Sciences, King Saud University in collaboration with Section of Obstetrics and Gynecology, King Khalid University Hospital (KKUH), Riyadh, KSA from October 2018 to December 2020. Instituitional Review Board, KKUH approved the study (E-18-3536). All experiments were performed in accordance with relevant guidelines and regulations. Informed consent was obtained from all the study participants including patients as well as control group participants. A trained interviewer administered a standard face-to-face questionnaire to each participant to obtain the potential factors that might reveal their body burden of metals, including sociodemographic information, lifestyle characteristics, anthropometry, and menstruation history. Pregnant women and women with diabetes mellitus and the taking of lipid-lowering or antihypertensive drugs, anemia, malignant neoplasia, any active infectious diseases or thromboembolism, stroke or history of ischaemic heart disease were excluded from the study.

\section{Sample collection and preliminary investigations}

Blood sample $(5 \mathrm{ml})$ was drawn from each subject participated in the study. The blood samples were subjected to centrifugation at $3000 \mathrm{rpm}$ for $15 \mathrm{~min}$ to obtain the serum. The serum samples were transferred in eppendorf tubes and stored at $-80^{\circ} \mathrm{C}$ until analysis. All the preliminary investigations including $\mathrm{CBC}$ and lipid profile wereanalysed in an Auto analyzer, Cell Dyne 3700 (STA compact, Mediserv, UK). Measurement of LH was done using Roche Elecsys 2010 Modular Analytics E170-Cobas e 411 utilizing electrochemiluminescence immunoassay (Roche Diagnostics, Germany).

\section{Determination of superoxide dismutase activity}

SOD activity was measured by SOD Assay Kit-WST (19160), Sigma. WST working solution and enzyme working solution were added to blank and study samples in a 96 well plate. After an incubation time for 20 minutes at $37^{\circ} \mathrm{C}$, absorbance was read at $450 \mathrm{~nm}$ using plate reader. SOD activity was calculated and expressed as $\mathrm{IU} / \mathrm{ml}$.

\section{Determination of Glutathione content}

Glutathione Assay Kit (CS0260) Sigma was used to estimate serum levels of glutathione .Principally, the kit employs a kinetic assay in which catalytic amounts (nmoles) of GSH cause a continuous reduction of 5,5'- 
dithiobis(2-nitrobenzoic acid) (DTNB) to TNB and the GSSG formed is recycled by glutathione reductase and $\mathrm{NADPH}$. The reaction rate is proportional to the concentration of glutathione up to $2 \mu \mathrm{M}$. The yellow product, 5-thio-2-nitrobenzoic acid (TNB) is measured spectrophotometrically at $412 \mathrm{~nm}$.

\section{Heavy metal analysis by Inductively Coupled Plasma Mass spectrophotometry (ICP-MS)}

Inductively Coupled Plasma Mass spectrophotometer (ICP/MS), Agilent Technologies 7700 was employed to assay levels of heavy metals in serum. Prior to analysis, serum samples $(400 \mu \mathrm{l})$ were centrifuged and diluted with solvent mix $(2.5 \mathrm{ml})$ consisting of $1 \%$ HNO3 and $0.01 \%$ Triton $\times 100$ (HPLC grade, Sigma Aldrich). Determination of all the heavy metals was done by running a calibration curve with detection range of $0.05-$ $100 \mathrm{ppb}$ (prepared from a standard stock solution $1000 \mathrm{ppb}$ ).

\section{Statistical analysis}

Statistical analysis was performed using Sigma Plot software. Sociodemographic data was analyzed by Wilcoxon Signed Rank test ascertain significant differences between the studied groups. Comparison of clinical characteristics, biochemical parameters and levels of heavy metals was performed by paired $t$ test. Pearsons correlation and multiple regression was applied to the study parameters inorder to investigate the role of heavy metals on antioxidant status.

\section{Declarations}

\section{Disclosure}

The authors report no conflicts of interest in this study.

\section{Acknowledgement}

The authors are thankful to Research Support and Services Unit, King Saud University for technical support.

\section{Funding}

This project was financially supported by Vice Deanship of Research chairs, King Saud University.

\section{Authors contribution}

Conceptualisation, Manal Abudawood; Sample collection, Lulu Abdullah Ali Alnuaim and Atheer H. Alanazi; Data curation, Hajera Tabassum, Lulu Abdullah Ali Alnuaim, Manal Abudawood; Methodology, Hajera Tabassum , Atheer H. Alanazi, Fatmah Almusallam, Naif D. Alenzi, Samyah T. Alanazi, Manal A. Alghamdi, Ghadah H. Altoum , Manar A. Alzeer, and Majed O. Alotaibi; Project administration, Manal Abudawood; Statistics, Mir Naiman Ali; Supervision, Manal Abudawood; Writing, Manal Abudawood and Hajera Tabassum; Review and editing, Feda Aljaser and Mir Naiman Ali.

\section{References}


1. Mortada, R., \&Williams, T. Metabolic Syndrome: Polycystic Ovary Syndrome. FP Essent. 435,30 (2015) .

2. Skrgatic, L., Baldani, D.P., Cerne, J., Ferk, P.,\& Gersak K. CAG repeat polymorphism in androgen receptor gene is not directly associated with polycystic ovary syndrome but influences serum testosterone levels. J Steroid Biochem Mol Bio/128,107 (2012)

3. Coskun, A., Arikan, T., Kilinc, M., Arikan, D.C., \&Ekerbiçer, H.C. Plasma selenium levels in Turkish women with polycystic ovary syndrome. Eur J Obstet Gynecol ReprodBio/168,183 (2013).

4. Chowdhury, S., Mazumder, M.A., Al-Attas, O, et al. Heavy metals in drinking water: Occurrences, implications, and future needs in developing countries. Sci Total Environ569, 476 (2016).

5. Mendola, P., Messer, L.C.,\& Rappazzo, K. Science linking environmental contaminant exposures with fertility and reproductive health impacts in the adult female. Fertil Steril. 89, e84 (2008)

6. Bloom, M.S., Louis, G.M., Sundaram, R., Kostyniak, P.J., \&Jain, J. Associations between blood metals and fecundity among women residing in New York State. Reprod Toxicol (Elmsford, NY) 31,158 (2011).

7. Chowdhury, B.A.\& Chandra, R.K. Biological and health implications of toxic heavy metal and essential trace element interactions. Prog Food NutrSci11,55 (1987).

8. Schoeters, G., Den Hond, E., Zuurbier, M., Naginiene, R., Van den Hazel, P., Stilianakis, N., et al. Cadmium and children: exposure and health effects. Acta Paediatr95, 50 (2006).

9. Holmes, P., James, K.A., \&Levy, L.S. Is low-level environmental mercury exposure of concern to human health? Sci Total Environ. 408, 171 (2009).

10. Sengupta, P., Banerjee, R., Nath, S., Das, S., \&Banerjee, S. Metals and female reproductive toxicity. Hum Exp Toxico/34, 679 (2015).

11. Rebolledo, J., Fierens, S., Versporten, A., et al. Human biomonitoring on heavy metals in Ath: methodological aspects. Arch Public Health69,10 (2011)

12. Gallagher, C.M., Moonga, B.S., \&Kovach, J.S. Cadmium, follicle-stimulating hormone, and effects on bone in women age 42-60 years, NHANES III. Environ Res. 110, 105 (2010)

13. Guo, Z., Guo, H., \&Xia, Y. Effects on endocrine system of female rats exposed to chronic arsenic. J Hyg Res. 40, 178 (2011).

14. Chang, S.H., Cheng, B.H., Lee, L., Chuang, H.Y., Yang, C.Y., Sung,F.C., et al. Low blood lead concentration in association with infertility in women. Environ Res.101, 380 (2006).

15. Jackson, L., Howards, P., Wactawski-Wende, J., \&Schisterman, E. The association between cadmium, lead and mercury blood levels and reproductive hormones among healthy, premenopausal women. Hum Reprod 26,2887 (2011).

16. Yedjou, G.C,\& Tchounwou, P.B.In vitro cytotoxic and genotoxic effects of arsenic trioxide on human leukemia cells using the MTT and alkaline single cell gel electrophoresis (comet) assays. Mol Cell Biochem301, 123(2007)

17. Tchounwou, P.B., Ishaque, A., Schneider, J. Cytotoxicity and transcriptional activation of stress genes in human liver carcinoma cells $\left(\mathrm{HepG}_{2}\right)$ exposed to cadmium chloride. Mol Cell Biochem222, 21 (2001)

18. Patlolla, A., Barnes, C., Yedjou, C., Velma, V., \&Tchounwou, P.B. Oxidative stress, DNA damage and antioxidant enzyme activity induced by hexavalent chromium in Sprague Dawley rats. Environ Toxicol 24, 66 (2009) 
19. Yedjou, G.C., \&Tchounwou, P.B. N-acetyl-cysteine affords protection against lead-induced cytotoxicity and oxidative stress in human liver carcinoma $\left(\mathrm{HepG}_{2}\right)$ cells. Int/ J Environ Res Pub Health4,132 (2008).

20. Sutton, D.J., \&Tchounwou, P.B.Mercury induces the externalization of phosphatidylserine in human proximal tubule (HK-2) cells. Intl J Environ Res Public Health4, 138 (2007)

21. Beyersmann, D.,\&Hartwig, A. Carcinogenic metal compounds: recent insight into molecular and cellular mechanisms.Arch Toxico/ 82, 493 (2008)

22. Hatch, E.E., Nelson, J.W., Stahlhut, R.W.,\&Webster, T.F.Association of endocrine disruptors and obesity: perspectives from epidemiological studies. Int J Andro/33, 324 (2010)

23. Ahmed Alobaidi, A.H., Abrahem, M.K., Ahmad, S.S., \&Alsamarai, A.M. Dyslipidemia and oxidative stress in Iraqi women with poly cystic ovary syndroms. World J Pharm Pharm Sci4,39 (2015).

24. Enechukwu. C.I., Onuegbu, A.J., Olisekodiaka, M.J., et al. Oxidative stress markers and lipid profiles of patients with polycystic ovary syndrome in a Nigerian tertiary hospital. Obstet Gynecol Sci. 62 , 335 (2019)

25. Bergman, A., Heindel, J., Jobling, S., Kidd, K., Zoeller, R.T. State-of-the-science of endocrine disrupting chemicals, Toxicol. Lett. 211, S3 (2012).

26. lavicoli, I., Fontana, L., \&Bergamaschi, A. The effects of metals as endocrine disruptors. J Toxicol Environ Health B Crit Rev12,206 (2009).

27. Forman, H.J., Zhang, H., \&Rinna, A. Glutathione: overview of its protective roles, measurement, and biosynthesis. Mol Aspects Med.30, 1 (2009).

28. Lushchak, VI. Glutathione homeostasis and functions: potential targets for medical interventions. $J$ Amino Acids. 2012,736837 (2012).

29. Lang, C.A., Mills, B.J., Mastropaolo, W.,\& Liu, M.C. Blood glutathione decreases in chronic diseases. J Lab Clin Med. 135,402 (2000).

30. Kirmizi, D.A., Baser, E., Turksoy, V.A., Kara, M., Yalvac, E.S., \& Gocmen, A.Y. Are Heavy Metal Exposure and Trace Element Levels Related to Metabolic and Endocrine Problems in Polycystic Ovary Syndrome? Biol Trace Elem Res. 198, 77 (2020)

31. Dinger, Y., Akcay, T., Erdem, T., Ilker Saygili, E., Gundogdu, S. DNA damage, DNA susceptibility to oxidation and glutathione level in women with polycystic ovary syndrome. Scand J Clin Lab Invest. 65, 721 (2005).

32. Mohammadi, M. Oxidative Stress and Polycystic Ovary Syndrome: A Brief Review. Int J Prev Med.10 (2019).

33. Barondeau, D.P., Kassmann, C.J., Bruns, C.K., Tainer, J.A.,\& Getzoff, E.D. Nickel superoxide dismutase structure and mechanism.Biochemistry 43,8038 (2004)

34. Yilmaz, N., Inal, H.A., Gorkem, U., Sargin Oruc, A., Yilmaz, S., \&Turkkani, A. Follicular fluid total antioxidant capacity levels in PCOS. J Obstet Gynaecol.36, 654 (2016).

35. Hilali, N., Vural, M., Camuzcuoglu, H., Camuzcuoglu, A., \&Aksoy, N. Increased prolidase activity and oxidative stress in PCOS. Clin Endocrinol (Oxf) 79, 105 (2013)

36. Zhang, D., Luo, W.Y., Liao,H., Wang, C.F., \&Sun, Y.The effects of oxidative stress to PCOS. Sichuan Da Xue Xue Bao Yi Xue Ban39, 421 (2008). 
37. Dos Santos, A.C.S., Azevedo, G.D., \&Lemos, T.M.A.M. The influence of oxidative stress in inflammatory process and insulin resistance in obese women with polycystic ovary syndrome. Trans/ Biomed7,4 (2016).

38. Kuşçu, N.K.,\& Var, A. Oxidative stress but not endothelial dysfunction exists in non-obese, young group of patients with polycystic ovary syndrome. Acta Obstet GynecolScand88,612 (2009).

39. Zheng, G., Wang, L., Guo, Z., Sun, L., Wang, L., Wang, C., Zuo, Z., \&Qiu, H. Association of Serum Heavy Metals and Trace Element Concentrations with Reproductive Hormone Levels and Polycystic Ovary Syndrome in a Chinese Population. Biol Trace Elem Res. 167,1 (2015).

40. Satarug, S., Baker, J.R., Urbenjapol, S., Haswell-Elkins, M., Reilly, P.E., Williams, D.J., \&Moore, M.R. A global perspective on cadmium pollution and toxicity in non-occupationally exposed population. Toxicol Lett.137, 65 (2003)

41. Chen, Y.W., Yang, C.Y., Huang, C.F., Hung, D.Z., Leung, Y.M., \&Liu, S.H.Heavy metals, islet function and diabetes development. Islets 1, 169 (2009)

42. Kurdoglu, Z., Kurdoglu, M., Demir, H., \&Sahin, H. Serum trace elements and heavy metals in polycystic ovary syndrome. Hum Exp Toxico/31,452(2012)

43. Anetor, J.I., Wanibuchi, H., \&Fukushima, S. Arsenic exposure and its health effects and risk of cancer in developing countries: micronutrients as host defence. Asian Pac J Cancer Prev. 8, 13 (2007).

44. Park, J.S., Ha, K.H., He, K., Kim, D.J., Moon, S.-S., Park, J.S., Ha, K.H., He, K., \& Kim, D.J. Association between blood mercury level and visceral adiposity in adults.Diabetes Metab. J. 41, 113(2017).

45. Farina, M., Avila, D.S., da Rocha, J.B.T., \& Aschner, M.Metals, oxidative stress and neurodegeneration: a focus on iron, manganese and mercury. Neurochem. Int. 62,575(2013)

46. Branco, V., Caito, S., Farina, M., Teixeira da Rocha, J., Aschner, M., \&Carvalho, C. Biomarkers of mercury toxicity: Past, present, and future trends. J Toxicol Environ Health B Crit Rev. 20, 119 (2017).

47. Roy, C., Tremblay, P.-Y.Y., \& Ayotte, P. Is mercury exposure causing diabetes, metabolic syndrome and insulin resistance? A systematic review of the literature.Environ. Res.156, 747(2017)

\section{Tables}


Table 1

Sociodemographic and clinical characteristics of the study groups

\begin{tabular}{|llll|}
\hline & Control & PCOS & \\
\hline & $\mathrm{n}(\%)$ & $\mathrm{n}(\%)$ & $P$ \\
\hline Age $($ mean \pm SD $)$ & $29.16 \pm 6.2$ & $30.41 \pm 6.8$ & $\mathrm{NS}$ \\
\hline Marital status & $\mathrm{NS}$ & & \\
\hline Married & $30(53)$ & $24(48)$ & \\
\hline Unmarried & $26(46.4)$ & $26(52)$ & \\
\hline Pregnancy & $2(3.57)$ & $1(2)$ & $\mathrm{NS}$ \\
\hline Irregular menses & $4(7.1)$ & $28(56)$ & $0.002^{\star *}$ \\
\hline Acne & $27(48.2)$ & $30(60)$ & $0.04^{\star}$ \\
\hline Skin pigmentation & $16(28.5)$ & $23(46)$ & $\mathrm{NS}$ \\
\hline Cases of nipple discharge & $4(7.1)$ & $\mathrm{NIL}$ & $\mathrm{NS}$ \\
\hline Oral contraceptives & $2(3.5)$ & $2(4)$ & NS \\
\hline History of Hypertension & $1(1.78)$ & $2(4)$ & NS \\
\hline Gestational Diabetes (GD) & $1(1.78)$ & $\mathrm{NIL}$ & NS \\
\hline Cardiovascular diseases (CVDs) & $1(1.78)$ & $\mathrm{NIL}$ & $\mathrm{NS}$ \\
\hline$* p \leq 0.05, * \star p \leq 0.01$, NS-Non-significant & & \\
\hline
\end{tabular}


Table 2

Biochemical characteristics of the study groups.

\begin{tabular}{|llll|}
\hline & Control & PCOS & $P$ \\
\hline Age & $29.16 \pm 6.2$ & $30.41 \pm 6.8$ & NS \\
\hline BMl & $25.0 \pm 6.08$ & $27.23 \pm 5.0$ & NS \\
\hline FBS $(\mathrm{mmol} / \mathrm{L})$ & $5.2 \pm 0.9$ & $6.88 \pm 1.49$ & $\mathrm{P}<0.001$ \\
\hline $\mathrm{HbA} 1 \mathrm{c}(\%)$ & $5.37 \pm 0.30$ & $6.70 \pm 0.22$ & $\mathrm{P}<0.001$ \\
\hline $\mathrm{TC}(\mathrm{mmol} / \mathrm{L})$ & $4.48 \pm 0.96$ & $4.36 \pm 0.9$ & 0.57 \\
\hline $\mathrm{TG}(\mathrm{mmol} / \mathrm{L})$ & $1.37 \pm 0.77$ & $1.89 \pm 0.32$ & $\mathbf{0 . 0 2 *}$ \\
\hline $\mathrm{HDL}(\mathrm{mmol} / \mathrm{L})$ & $1.31 \pm 0.35$ & $1.24 \pm 0.34$ & 0.32 \\
\hline $\mathrm{LDL}(\mathrm{mmol} / \mathrm{L})$ & $2.50 \pm 0.84$ & $2.79 \pm 0.98$ & 0.09 \\
\hline $\mathrm{LH}(\mathrm{mmol} / \mathrm{L})$ & $2.95 \pm 0.75$ & $6.73 \pm 0.1$ & $\mathrm{P}<\mathbf{0 . 0 0 1}$ \\
\hline \multirow{2}{*}{${ }^{*} \mathrm{P} \leq 0.05, \mathrm{NS}=$ non-significant } & & \\
\hline
\end{tabular}

Table 3

Serum levels of antioxidant markers and heavy metals among the study groups

\begin{tabular}{|llll|}
\hline & Control & PCOS & $P$ \\
\hline SOD $(\mathrm{IU} / \mathrm{ml})$ & $17.39 \pm 3.35$ & $9.30 \pm 3.2$ & $<0.001$ \\
\hline GSH $(\mathrm{mg} / \mathrm{ml})$ & $8.09 \pm 1.39$ & $6.24 \pm 1.50$ & $<0.001$ \\
\hline $\mathrm{As}(\mathrm{ppb})$ & $1.95 \pm 0.34$ & $2.68 \pm 0.50$ & $<0.001$ \\
\hline $\mathrm{Cd}(\mathrm{ppb})$ & $0.59 \pm 0.22$ & $1.75 \pm 0.44$ & $<0.001$ \\
\hline $\mathrm{Pb}(\mathrm{ppb})$ & $36.69 \pm 6.57$ & $83.19 \pm 14.4$ & $<0.001$ \\
\hline $\mathrm{Hg}(\mathrm{ppb})$ & $5.0 \pm 1.08$ & $14.55 \pm 2.99$ & $<0.001$ \\
\hline
\end{tabular}


Table 4

Correlation coefficients values between oxidative stress markers, metabolic markers and heavy metals in PCOS group.

\begin{tabular}{|c|c|c|c|c|c|c|}
\hline & \multirow{2}{*}{$\begin{array}{l}\text { As } \\
\mathrm{r}(P)\end{array}$} & \multirow{2}{*}{$\begin{array}{l}\mathrm{Cd} \\
\mathrm{r}(P)\end{array}$} & \multirow{2}{*}{$\begin{array}{l}\mathrm{Pb} \\
\mathrm{r}(P)\end{array}$} & \multirow{2}{*}{$\begin{array}{l}\mathrm{Hg} \\
\mathrm{r}(P)\end{array}$} & \multirow{2}{*}{$\begin{array}{l}\text { SOD } \\
\mathrm{r}(P)\end{array}$} & \multirow{2}{*}{$\begin{array}{l}\text { GSH } \\
\mathrm{r}(P)\end{array}$} \\
\hline & & & & & & \\
\hline BMI & $0.06(0.73)$ & $0.06(0.74)$ & $0.23(0.20)$ & $0.29(0.11)$ & $0.04(0.8)$ & $0.17(0.30)$ \\
\hline FBS & $0.09(0.50)$ & $-0.02(0.88)$ & $-0.03(0.78)$ & $0.29(0.004)^{\star *}$ & $-0.26(0.06)$ & $-0.19(0.18)$ \\
\hline $\mathrm{HbA1c}$ & $0.01(0.90)$ & $0.22(0.12)$ & $-0.18(0.18)$ & $0.27(0.05)^{*}$ & $-0.32(0.02)^{*}$ & $0.006(0.99)$ \\
\hline TC & $-0.09(0.49)$ & $0.30(0.02) *$ & $-0.05(0.68)$ & $0.14(0.30)$ & $0.11(0.43)$ & $0.02(0.84)$ \\
\hline TG & $0.02(0.84)$ & $-0.07(0.62)$ & $0.02(0.85)$ & $0.01(0.30)$ & $0.13(0.33)$ & $-0.19(0.17)$ \\
\hline HDL & $-0.02(0.86)$ & $-0.19(0.18)$ & $-0.07(0.61)$ & $-0.03(0.80)$ & $-0.04(0.77)$ & $0.14(0.32)$ \\
\hline LDL & $0.007(0.96)$ & $-0.18(0.20)$ & $-0.01(0.96)$ & $0.15(0.2)$ & $0.10(0.48)$ & $0.004(0.97)$ \\
\hline LH & $0.003(0.84)$ & $-0.19(0.17)$ & $-0.16(0.25)$ & & $0.03(0.007)^{\star *}$ & $-0.02(0.86)$ \\
\hline SOD & $-0.1(0.04)^{\star *}$ & $-0.11(0.40)$ & $-0.32(0.02) *$ & $-0.16(0.21)$ & - & $-0.04(0.73)$ \\
\hline GSH & $-0.41(0.002) * \star$ & $-0.16(0.22)$ & $-0.24(0.04) *$ & $-0.023(0.0098) *$ & $-0.04(0.73)$ & - \\
\hline${ }^{\star} p \leq$ & $p \leq c$ & & & & & \\
\hline
\end{tabular}

Table 5

Inter-element relationship of heavy metals in PCOS cases

\begin{tabular}{|llll|}
\hline & As & $\mathrm{Cd}$ & $\mathrm{Pb}$ \\
& $\mathrm{r}(p)$ & $\mathrm{r}(p)$ & $\mathrm{r}(p)$ \\
\hline $\mathrm{Cd}$ & $0.54(p<0.001)$ & - & $0.29(0.02)^{\star}$ \\
$\mathrm{Pb}$ & $0.54(p<0.001)$ & $0.29(0.02)^{\star}$ & - \\
\hline $\mathrm{Hg}$ & $0.47(p<0.001)$ & $0.52(p<0.001)$ & $0.44(p<0.001)$ \\
\hline
\end{tabular}

\section{Figures}




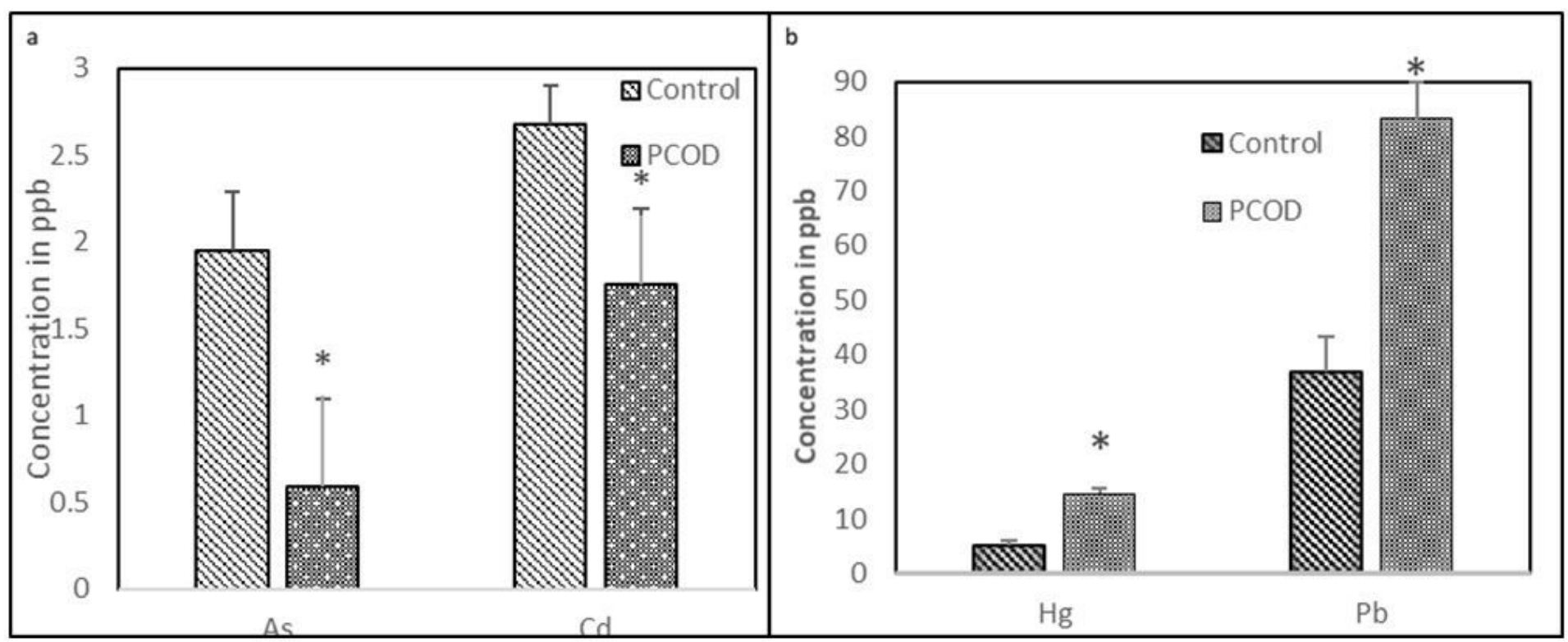

Figure 1

Serum concentrations of heavy metals in control and PCOS groups 


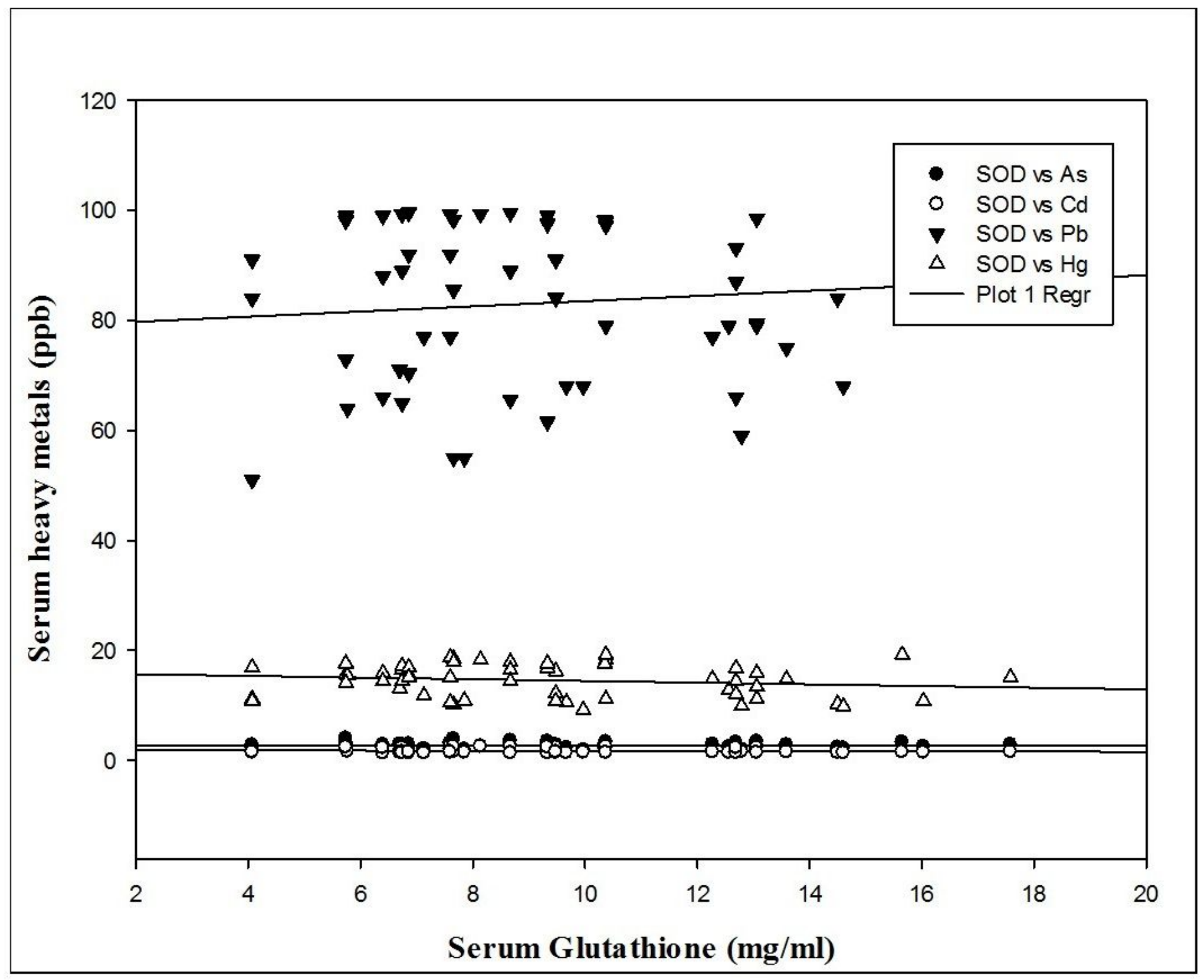

Figure 2

Multiple regression plot of heavy metals and GSH in PCOS group 


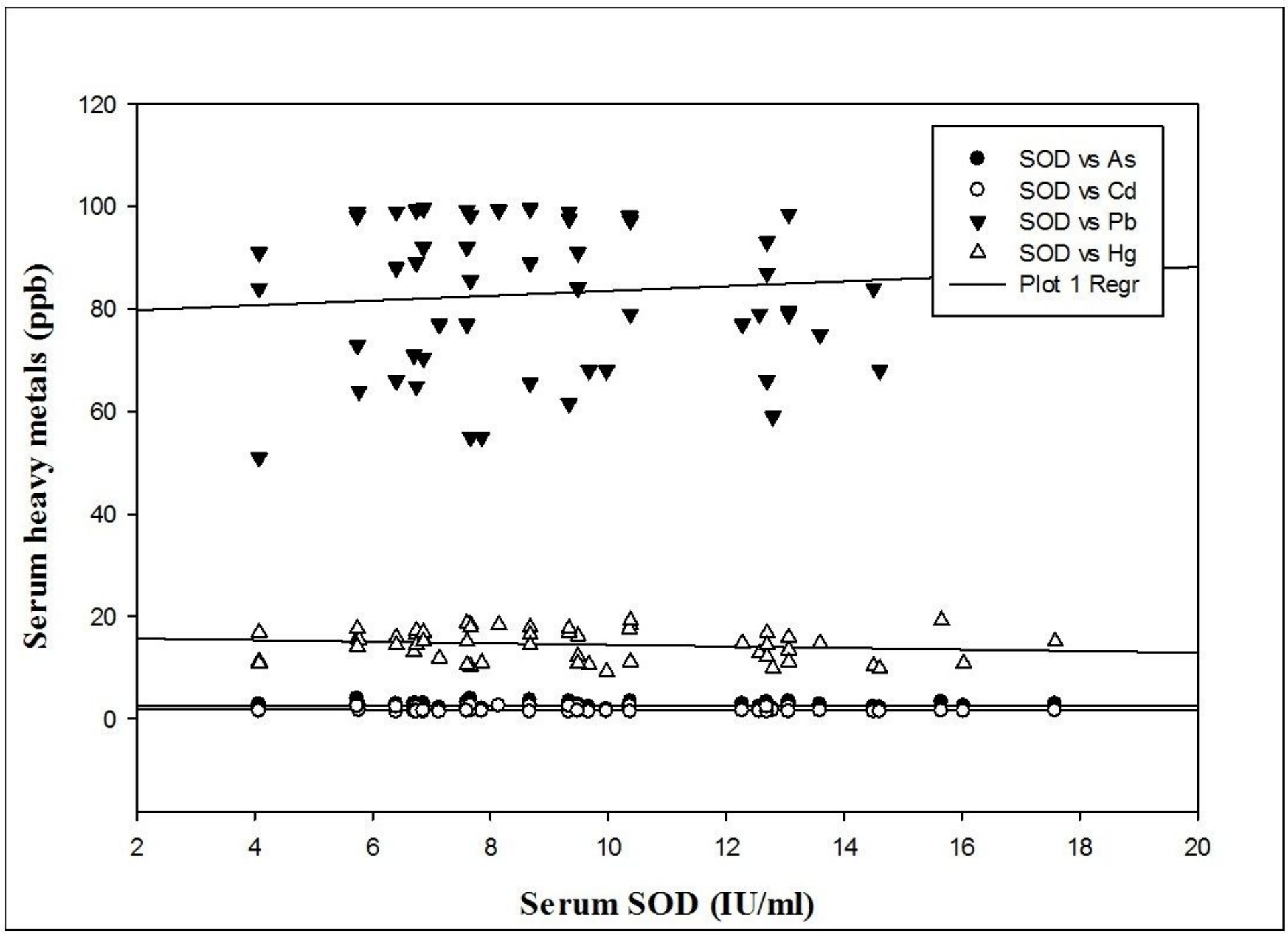

Figure 3

Multiple regression plot of heavy metals and SOD in PCOS group 